\title{
Erratum to: Phosphate homeostasis and its role in bone health
}

\author{
Maria Goretti Pinedo ${ }^{1}$ - Uri S. Alon ${ }^{2}$
}

Published online: 6 July 2017

(C) IPNA 2017

Erratum to: Pediatr Nephrol (2012) 27:2039-2048

DOI 10.1007/s00467-012-2175-z

Owing to an error in typesetting, the name of the first author of this article was rendered incorrectly. Her correct name is Maria Goretti Penido.

The online version of the original article can be found at http://dx.doi.org/ $10.1007 / \mathrm{s} 00467-012-2175-\mathrm{z}$

Uri S. Alon

ualon@cmh.edu

1 Pediatric Nephrology Unit, Clinics Hospital, School of Medicine, Federal University of Minas Gerais,

Belo Horizonte, Brazil

2 Bone and Mineral Disorders Clinic, Section of Pediatric Nephrology, Childrens Mercy Hospital and Clinics, University of Missouri at Kansas City,

2401 Gillham Road,

Kansas City, MO 64108, USA 